\title{
Spirally fluted tubing : prediction and measurement
}

\author{
Lu Cheng, T.J. Craft, B.E. Launder and M.A. Leschziner \\ Department of Mechanical Engineering, UMIST, PO Box 88, Manchester, M60 1QD, UK
}

\section{INTRODUCTION}

The spirally fluted tubing devised by Yampolsky [1] and shown in figure $l$ is perhaps unique among existing passive heat-transfer promoters in not raising the friction factor simultaneously with the effective Nusselt number. Figure 2 , taken from 1, shows the collected data on this type of tubing over a range of Reynolds numbers. The unanimous conclusion to emerge from the studies is that, depending on circumstances, heat transfer coefficients may be raised from $30 \%$ to $200 \%$ without any increase in wall friction factor; indeed many studies have reported a decrease in $f$.

The present contribution, comprising both numerical and experimental studies, has been aimed at explaining the underlying causes for this highly desirable behaviour.

It expands, on the experimental side, the studies of Larue et al. [2] by extending both mean and fluctuating velocity data to the near flute region which is so crucial to the heat transfer process. On the computational front, also, the present study extends our earlier work, BARBA et al. [3], by adopting a second-moment turbulence model in place of the two equation eddy viscosity scheme employed in that earlier exploration. This has enabled features of the flow field to be captured that simply lie outside the scope of eddy viscosity models. In what follows, Section 2 describes the experimental programme while Section 3 reports both the computational method and the model of turbulent transport contained therein. Results from both the computational and experimental studies are presented in Section 4 and the main conclusions are reported in Section 5 .

\section{THE EXPERIMENTAL PROGRAMME}

\subsection{Manufacture of Spirally Fluted Tube}

The original study of Larue et al. [2] had employed a section of the commercial tube section to undertake their velocity field measurements. This had the great disadvantage that the tubing was only $25 \mathrm{~mm}$ in diameter and this precluded any near surface studies. Accordingly, the present study determined to fabricate specially a section that was at least $100 \mathrm{~mm}$ in diameter to allow a sufficiently large flute structure for flow measurement in its vicinity to be made with commercially available hot wires.

Considerable effort was put into exploring alternative manufacturing techniques. In the end, a complex four-stage casting process was developed, HOSKER \& JACKSON [4] that produced an enlarged replica of the spirally fluted tube on the inside or a standard plastic $125 \mathrm{~mm}$ pipe, fig. $\mathrm{Ib}$.

\subsection{Instrumentation, Apparatus and Procedure}

The apparatus consisted of two straight pipe sections $15 \mathrm{~m}$ in length, connected by a U-bend and mounted one above

Tube à cannelures en spirales : prédiction et mesure

Le tube de Yampolsky à cannelures en spirale permet d'obtenir des performances remarquables en matière de transfert de chaleur. Des accroissements du transfert de chaleur de 50 à $300 \%$ par rapport à un tube lisse sont obtenues quand le facteur de frottement correspondant est réduit ou, au pire, non accru par rapport à celui d'un tube lisse.

Cet article fournit des données expérimentales et calculées détaillées sur le champ de vitesse moyenne et ses fluctuations dans les tubes à cannelures en spirales. Cela permet d'expliquer pour la première fois le comportement observé. Les calculs de transfert de chaleur montrent que, conformément aux résultats expérimentaux, c'est la conjugaison d'un nombre de Prandtl spécialement élevé et du passage à travers un tube à cannelures en spirales qui améliore le transfert. 


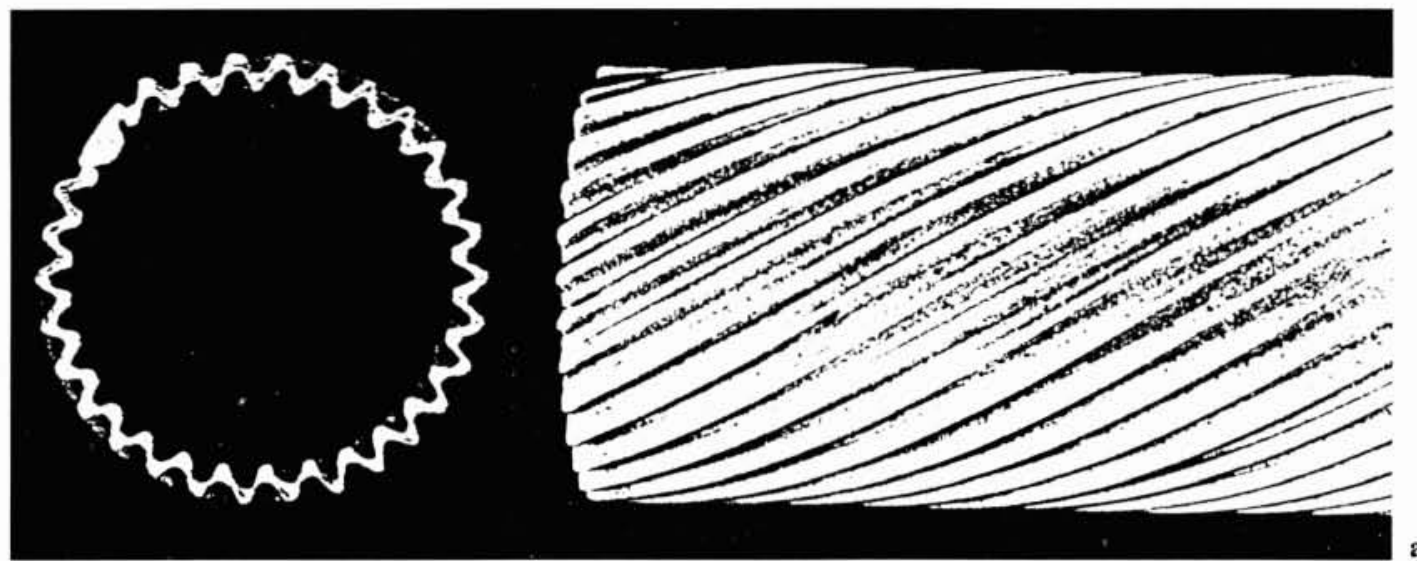

a)

1. Spirally fluted tubing

a) Yampolsky's $25 \mathrm{~mm}$ commercial tubing

b) Cast laboratory version, $125 \mathrm{~mm}$ dia.

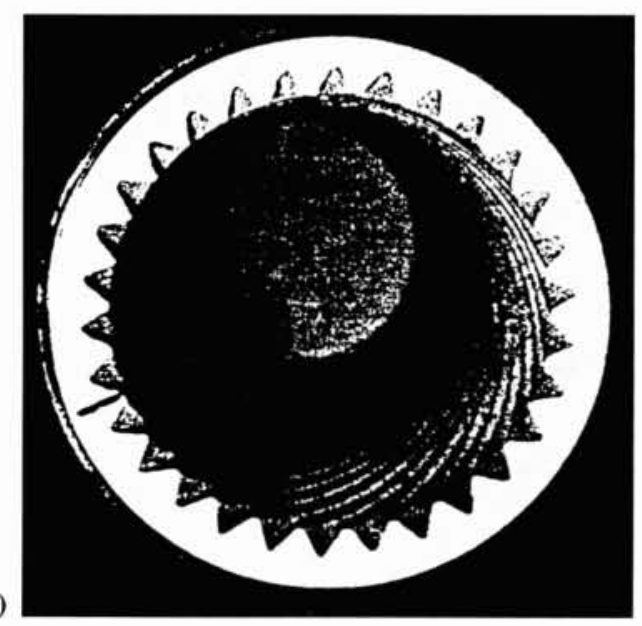

b)

the other. The smooth upper pipe, which was connected to a centrifugal fan, was used for flow metering, the downstream end incorporating a section where appropriate orifice plates could be installed. The return leg of the pipe comprised the spirally fluted tubing shown in fig. $1 b$, approximately 140 hydraulic diameters in all. Within and immediately after the $U$ bend honeycombs and screens were placed to achieve a nearly axisymmetric velocity distribution with negligible secondary flow. All measurements were taken by introducing the sensor probes into the open downstream end of the spirally fluted tube. The development of the flow was traced by successively adding sections of the spiral tubing though here attention is on the fully developed state measured at 139 effective diameters downstream. Details of the developing flow are reported by CHEAH et al. [5].

The hot-wire probe used initially was a DANTEC 55P61 $\mathrm{X}$-array, using a $1.25 \mathrm{~mm}$ long, $5 \mu \mathrm{m}$ dia tungsten wire with $1 \mathrm{~mm}$ inter-wire spacing. However, within the flute recesses it was felt that this particular probe, given the restricted measuring location, had inadequate spatial resolution and could give rise to blockage effects. Subsequently a TSI $1247 \mathrm{~A}$ X-array miniature probe was used to take detailed measurements within the valley region. This probe uses a $1.5 \mathrm{~mm}$ gold plated, $4 \mu \mathrm{m}$ dia tungsten wire with a sensor spacing of only $0.5 \mathrm{~mm}$. Velocity measurements were performed with a two channel TSI IFA 100 system comprising a Model 150 anemometer and signal condi-
2. Enhancement of $30^{\circ}$ helix for varied heat flux (does not include area extension). 
tioner interfaced via a 12 -bit $\mathrm{ADC}$ to a $386 \mathrm{sx}$ computer. The probe was calibrated for both velocity $(10 \mathrm{~m} / \mathrm{s}$ max.) and yaw angle $\left(35^{\circ} \sim 55^{\circ}\right)$ using a TSI air flow calibrator ; the typical calibration error was in the region of $1.5 \%$ over the calibration range. The calibrator settings were verified by using a MKS Baratron differential pressure transducer and signal conditioner whose transducer has a resolution of $0.00014 \mathrm{~cm} \mathrm{H}_{2} \mathrm{O}$ over the range $0-10 \mathrm{~mm} \mathrm{Hg}$. This instrument was also used to measure the static pressure in the flute valley at $0.974 \mathrm{~m}$ intervals along the pipe. These readings were used to establish the pipe friction factors.

The probe calibration was checked at the start (and end) of each measurement traverse. The probe was then inserted in a three component manual traversing unit with a resolution of $0.1 \mathrm{~mm}$ situated at the end of the test section with the probe axis aligned along the pipe flutes. Next, the pump was started and allowed to warm up for a period of $30 \mathrm{~min}$ before the flow rate was regulated by means of a bleed valve situated well upstream of the orifice measurement section. Once the flow had stabilized measurements began. Mean and turbulent velocities are based on averages of 7,500 samples per point accumulated at 1,000 samples per second.

\section{III $\square$ COMPUTATIONAL PROGRAMME}

The flow has been computed with an extended version of the steady-state STREAM code described by LIEN \& LESCHZINER [6], which employs a fully collocated, nonorthogonal grid arrangement. To prevent oscillations arising from the decoupling of pressure gradients and velocities due to the collocated grid, RHIE \& CHOW [7] interpolation is used when computing mass fluxes across cell faces. The algorithm iterates the solution to a steady state by the SIMPLE pressure correction of PATANKAR [8], and approximates convection with LEONARD's [9] QUICK and van LEERS [10] MUSCL schemes for mean momentum and turbulence quantities respectively.

Despite the three-dimensional nature of the flow, the fully-developed state can be computed as a twodimensional problem by setting the gradients of dependent variables to zero in the direction aligned with the flutes. The solution domain consists of a segment containing one flute, and periodic boundary conditions are applied at the segment boundaries by exchanging values between the two boundaries.

The near-flute portion of a typical 90 (radial) $\times 40$ (circumferential) gird is shown in figure 3. Away from the flute, the domain is covered by a simple cylindrical grid, although this is deformed in the flute region to match the geometry of the pipe wall. A fine grid is used close to the wall in order to resolve adequately the steep gradients that occur in that region. Finer grids up to $120 \times 80$ lines have also been used, but results on these show that the coarser mesh provides essentially grid-independent results. The effect of grid skewness in the flute region was also investigated by using grids with straight radial grid lines. This resulted in much greater grid skewness, yet the computed results were virtually identical to those obtained with the grid in figure 3 .

Convergence rates were initially extremely slow, particularly when a large number of circumferential nodes was

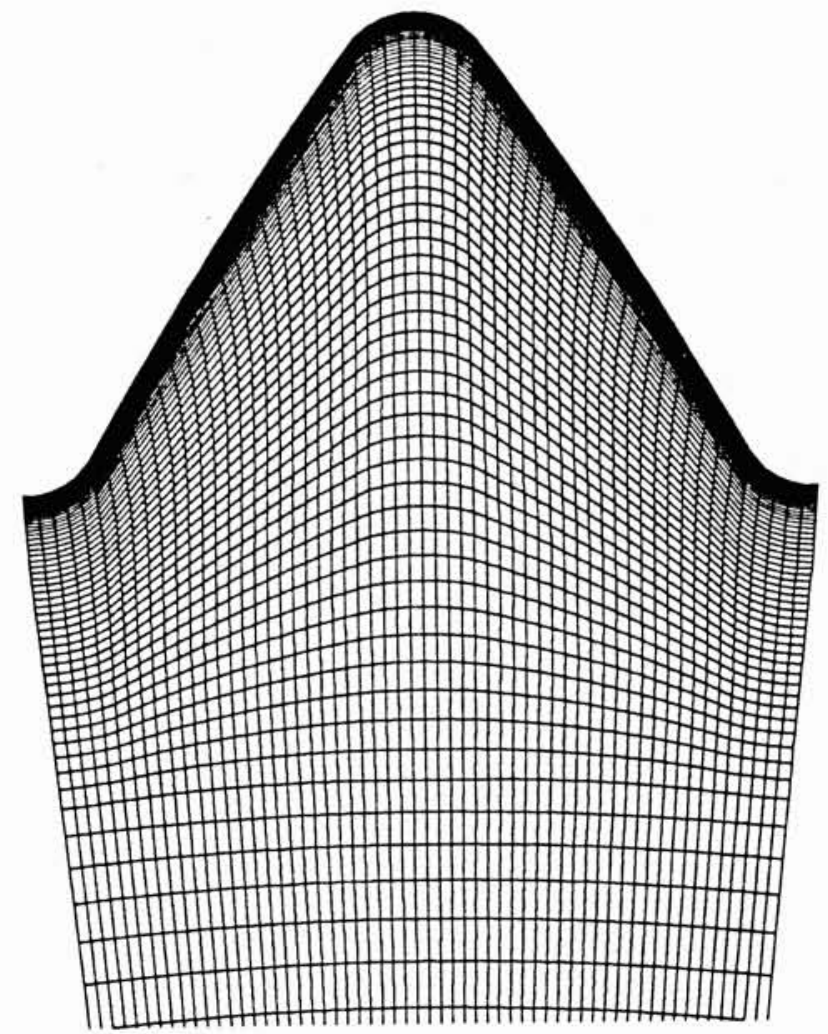

\section{Near-flute region of a typical grid.}

used. This was found to be due to the fact that the discretized equations were dominated, particularly at smaller radial distances, by the coefficients linking circumferentially adjacent nodes. The response to diffusion in the radial direction was therefore very weak. Based on the observation that the flow in the inner core only varied in the radial direction, a 1-D (radial) solution was adopted in this region, and this avoided the above problem.

\subsection{Turbulence Modelling}

Different turbulence models have been employed depending upon whether one is describing mixing in the lowReynolds-number sublayer or in the high-Reynolds- number region beyond. Within the sublayer, the low-Reynoldsnumber eddy viscosity model of LAUNDER \& SHARMA [11] is adopted together with the assumption of a uniform turbulent Prandtl number of 0.9. Beyond this region a second moment closure is adopted in which transport equations are solved for the six Reynolds stresses and the turbulence energy dissipation rate equation. The form of these equations may be written :

$$
\begin{gathered}
U_{k} \frac{\partial \overline{u_{i} u_{j}}}{\partial x_{k}} \equiv C_{i j} \equiv P_{i j}+d_{i j}+\phi_{i j}+\phi_{i j}^{(0)}-\frac{2}{3} \varepsilon \delta_{i j} \\
U_{k} \frac{\partial \varepsilon}{\partial x_{k}}=-c_{\varepsilon 1} \frac{\varepsilon^{2}}{k}+c_{\varepsilon 2} \frac{\varepsilon P_{k k}}{2 k}+d_{\varepsilon} \\
\text { where } P_{i j}=-\left(\overline{u_{i} u_{k}} \frac{\partial U_{j}}{\partial x_{k}}+\overline{u_{j} u_{k}} \frac{\partial U_{i}}{\partial x_{k}}\right)
\end{gathered}
$$


The model is based on that proposed by GIBSON \& LAUNDER [12], although the wall-reflection fragment $\phi_{i j}^{(0)}$ is the alternative recommended by CRAFT \& LAUNDER [13] which gives significant improvements in impinging flows and equally as good behaviour as the original in flows parallel to walls. The model can be written as

$$
\begin{aligned}
\phi_{i j}= & -1.8 \varepsilon a_{i j}-0.6\left[P_{i j}-C_{i j}-1 / 3\left(P_{k k}-C_{k k}\right) \delta_{i j}\right] \\
\phi_{i j}^{(0)}= & 0.5 \frac{\varepsilon}{k} \overline{\left(u_{m} u_{l}\right.} n_{m} n_{l}-3 / 2 \overline{u_{i} u_{m}} n_{m} n_{j} \\
- & \left.3 / 2 \overline{u_{j} u_{m}} n_{m} n_{i}\right) f_{y}-0.08 \frac{\partial U_{l}}{\partial x_{m}} \overline{u_{l} u_{m}}\left(\delta_{i j}-3 n_{i} n_{j}\right) f_{y} \\
& -0.01 k\left(\frac{\partial U_{k}}{\partial x_{m}} n_{l} n_{k} a_{l m} \delta_{i j}-\frac{3}{2} \frac{\partial U_{i}}{\partial x_{m}} n_{l} n_{j} a_{l m}\right. \\
& \left.-\frac{3 \partial U_{j}}{2 \partial x_{m}} n_{l} n_{i} a_{l m}\right) f_{y}+0.4 k \frac{\partial U_{l}}{\partial x_{m}} n_{l} n_{j}\left(n_{i} n_{j}-1 / 3 \delta_{i j}\right) f_{y}(4)
\end{aligned}
$$

where

$$
f_{y}=k^{3 / 2} /(2.5 \varepsilon y)
$$
vector

and $n_{k}$ denotes the direction cosine of the wall normal

$$
\begin{gathered}
d_{i j}-\frac{\partial}{\partial x_{k}}\left(0.22 \frac{k}{\varepsilon} \overline{u_{k} u_{l}} \frac{\overline{\partial u_{i} u_{j}}}{\partial x_{l}}\right) \\
d_{\varepsilon}=\frac{\partial}{\partial x_{k}}\left(0.18 \frac{k}{\varepsilon} \overline{u_{k} u_{l}} \frac{\partial \varepsilon}{\partial x_{l}}\right)
\end{gathered}
$$

In applying the wall-reflection model, it is necessary to define the unit vector normal to the wall $n$. Although it is obvious how to interpret $n$ when there is a single plane wall, it is not immediately apparent how to determine it in the complex geometry of the present case. For the present initial calculations, an approximate method of determining $n$ was used. In the core region, away from the flute, it is reasonable to suppose that the flow is essentially insensitive to the precise geometry of the pipe wall, and hence in this region $n$ was taken as the radial unit vector. In the near-flute region, the normal distance from the wall was simply approximated as the length of the « radial " gridline extending from the point in question to the intersection of that grid-line with the wall. An interpolation between these two practices has been adopted in the region where $0.7<r / R<0.8$ to give a smoothly varying function.

To compute the heat-transfer, a similar modelling approach was adopted, in that a second-moment closure was used in the fully turbulent region, and this was interfaced to a simple eddy-diffusivity model in the near-wall region. The second moment heat-flux model used can be written as

$$
U_{k} \frac{\overline{\partial u_{i} \theta}}{\partial x_{k}}=P_{i \theta}+d_{i \theta}+\phi_{i \theta}
$$

where

$$
P_{i \theta}=-\left(\overline{u_{k} \theta} \frac{\partial U_{i}}{\partial x_{k}}+\overline{u_{i} u_{k}} \frac{\partial T}{\partial x_{k}}\right)
$$

$$
\begin{aligned}
& \phi_{i \theta}=-3.0 \frac{\varepsilon}{k} \overline{u_{i} \theta}+0.5 \overline{u_{k} \theta} \frac{\partial U_{i}}{\partial x_{k}} \\
& d_{i} \theta=\frac{\partial}{\partial x_{k}}\left(0.18 \frac{k}{\varepsilon} \overline{u_{k} u_{l}} \frac{\overline{\partial u_{i} \theta}}{\partial x_{l}}\right)
\end{aligned}
$$

At the pipe wall, a constant heat-flux boundary condition was applied, and a turbulent Prandtl number of 0.9 was prescribed in the region where the eddy diffusivity model was used. In fact, the Nusselt number is predominantly determined by the mean and turbulent velocity field and the turbulent Prandtl number because most of the thermal resistance arises from the region where the eddy-viscosity model is used. The agreement of the computations with experiments are thus little affected by equations (9) and (10).

\section{COMPARISON OF MEASURED AND COMPUTATIONAL RESULTS}

Figures 4-6 compare profiles of measured and computed mean and turbulent velocity profiles across the pipe along a radial line passing through the flute trough. The measurements have all been obtained at a distance of 140 hydraulic diameters downstream from the start of the spirally fluted piping. Such a seemingly inordinate length from the origin is required to achieve fully developed flow due to the coupling between the swirl and axial flow, CHEAH et al. [5].

A striking feature of the flow pattern is that, unlike a fully developed laminar swirling pipe flow, the circumferential velocity $W$ does not increase linearly with radius, figure 4. Any eddy-viscosity based approach to computing this flow will, of course, generate such a linear profile but we note that the present Reynolds stress model gives a roughly parabolic variation of $W$ over most of the flow, broadly in line with the measurements. Close to the flute there is an interesting departure from the smooth variation over the remainder of the tube. The steep rise and fall in velocity observed in the experiments is well matched by the computations except very close to the wall, a feature on which we comment in the next paragraph.

The mean axial velocity profiles are compared in figure 5. Again agreement between the measured and computed profile is quite close except in the vicinity of the

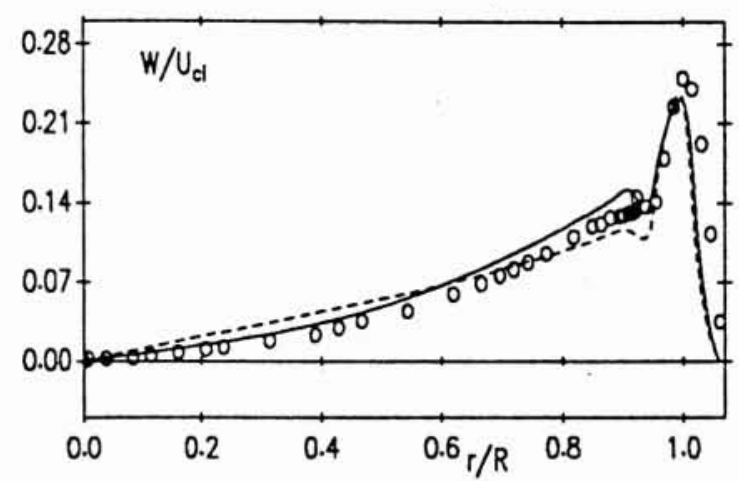

4. Swirl velocity profiles ...- Eddy viscosity model - Reynolds strass transport model. 

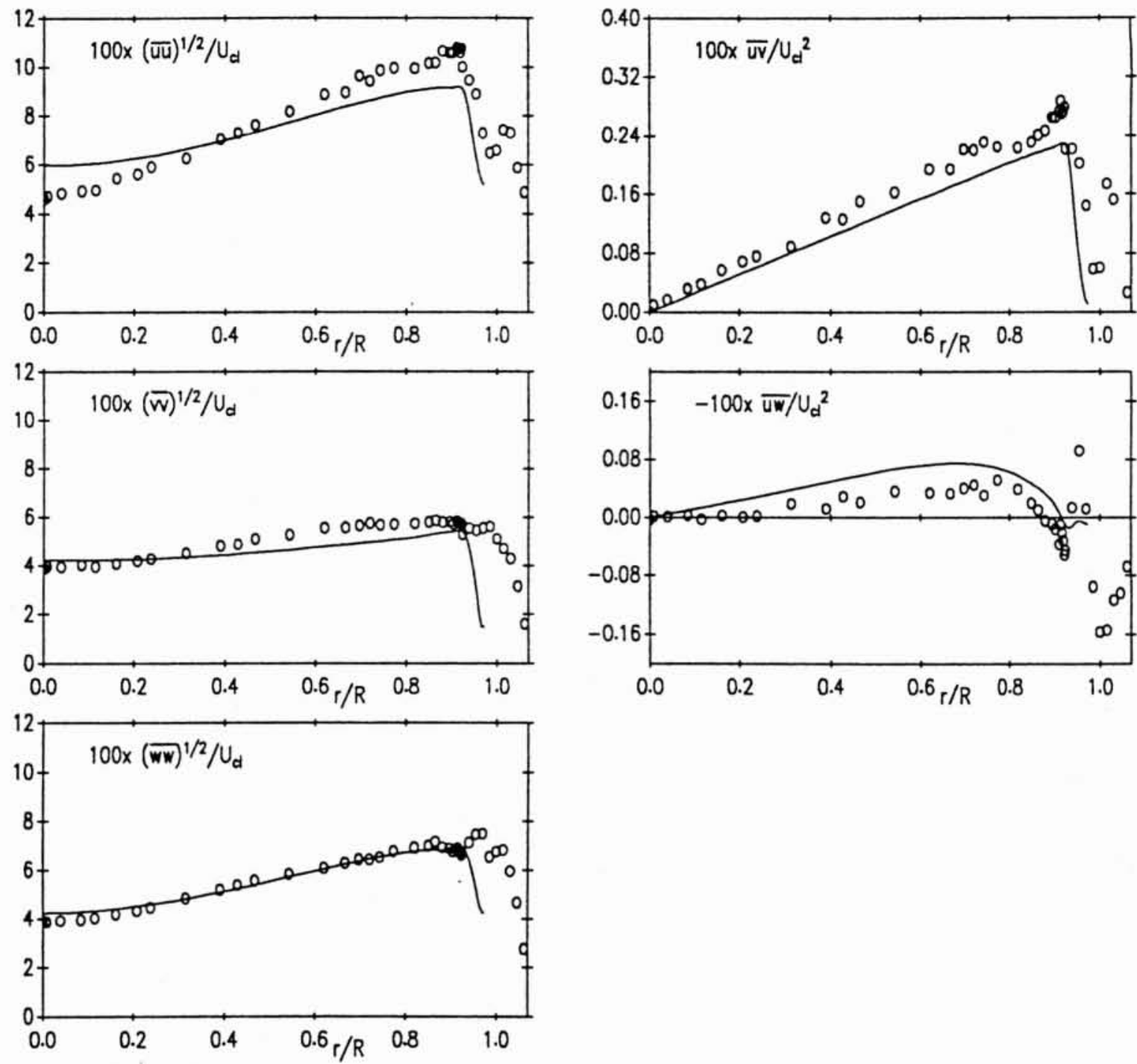

6. Shear and normal stress profiles across flute.

flutes. Although this may reflect insufficient effects of secondary convection in the computed velocity profile we cannot rule out the possibility of extra heat from the hot wire being transferred by radiation to the wall giving a spuriously high apparent velocity (This question is currently being examined at UMIST). The error would be particularly severe in this V-shaped recess with the wire being surrounded on three sides by the wall at ambient temperature. The computed and measured stress profiles are compared in figure 6 . Across the five stress profiles shown, agreement between the measured and computed profiles is generally satisfactory including the weak $\overline{u w}$ component which (because of its small magnitude) is normalized by the friction velocity $U_{\tau}$ rather than the centre-line velocity ( $\left.{ }^{1}\right)$.

(') The tangential stress $\overline{v w}$ which is not shown is exactly zero in the fully developed core flow.

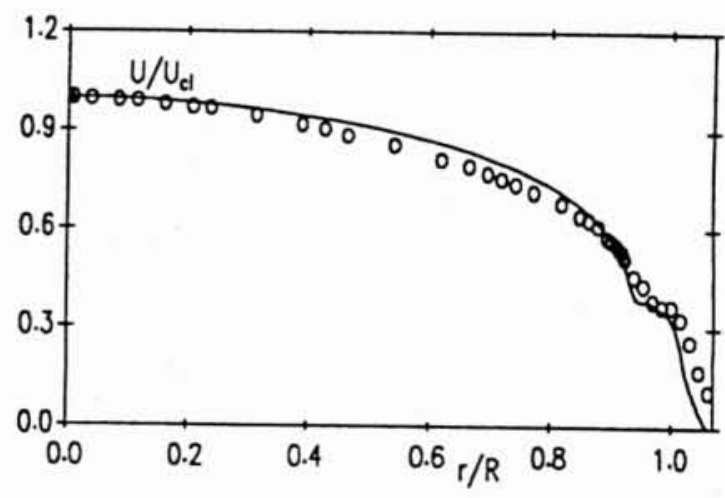

5. Mean axial velocity profile.

Figure 7 compares the computed and measured contours of the magnitude of the mean velocity in the vicinity of the flutes. There are striking similarities between the computed 

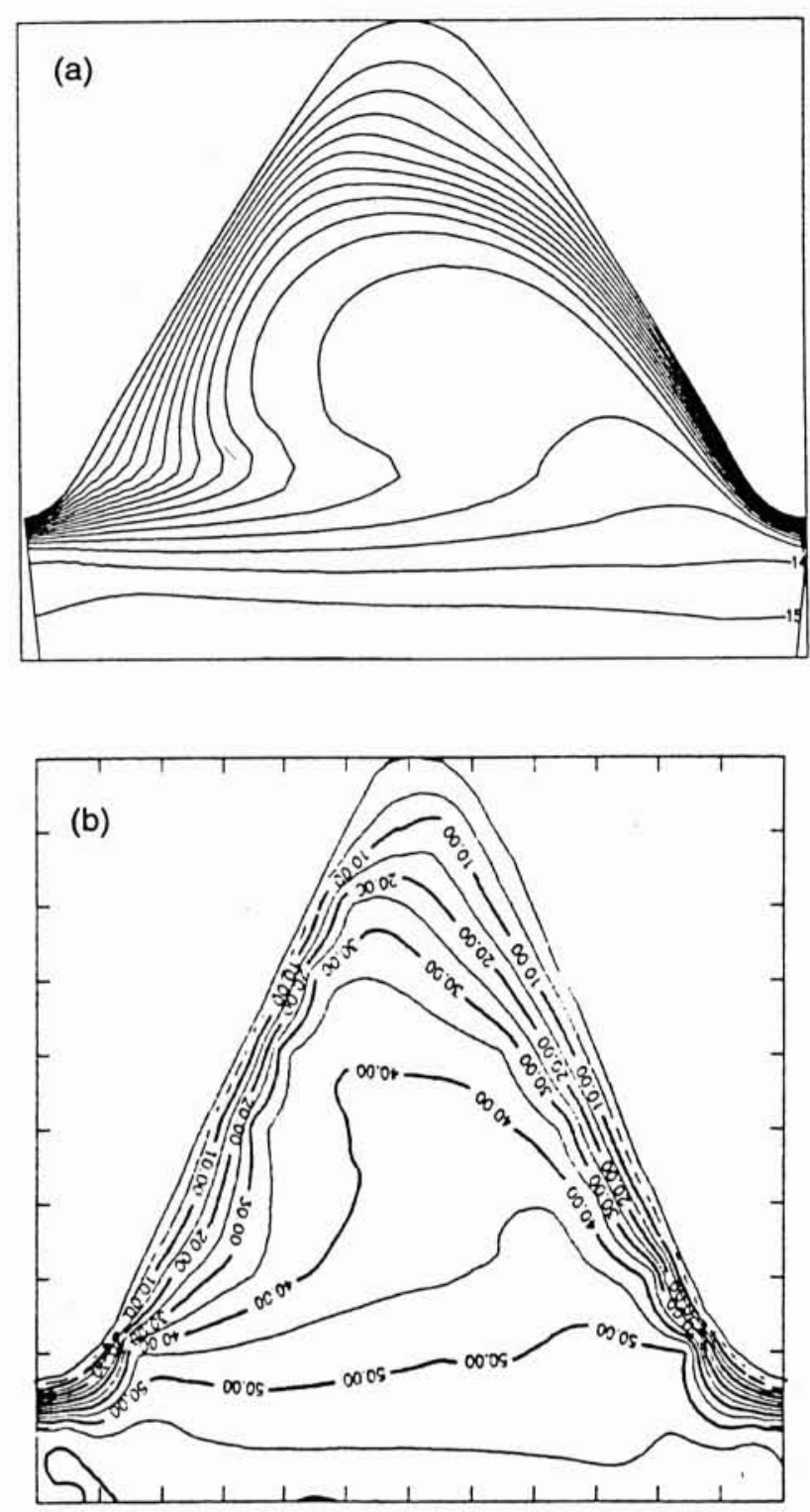

7. Contours of total velocity magnitude
a) Computation
b) Experiment.

and measured flow patterns but also clear differences as well. For example, on the pressure (right) side of the flute considerably steeper velocity contours are predicted than are measured. However, on the whole the above comparisons of the velocity field point to an encouraging degree of accord between the present computations and the measurements.

Turning attention to the heat-transfer predictions, figure 8 shows the distribution of local Nusselt number around the flute at two different Prandtl numbers, where the Nusselt number is defined as

$$
N u=\frac{\rho q_{w} D_{h}}{\alpha\left(T_{w}-T_{b l k}\right)} \frac{P}{2 \pi R}
$$

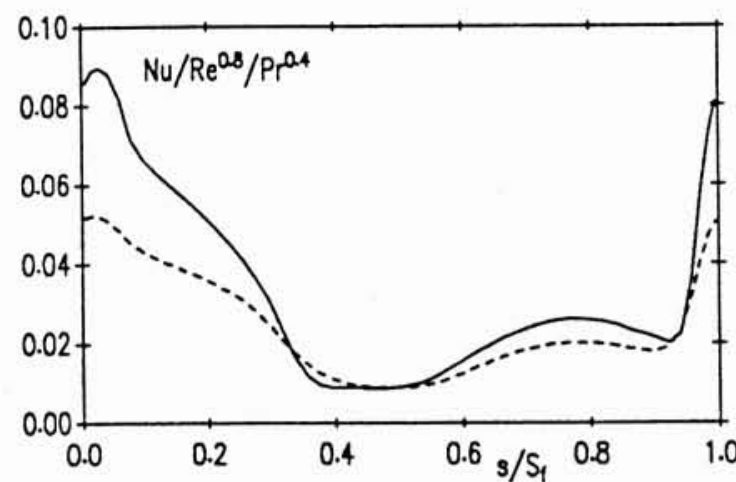

8. Nusselt number distributions

$$
\begin{aligned}
& -\cdots \operatorname{Pr}=0.71 \\
& -\operatorname{Pr}=5.0 .
\end{aligned}
$$

where $P$ is the perimeter of the tube and the factor $P /(2 \pi R)$ is included to account for the enhancement in area due to the fluting. As can be seen from the figure, there is a peak in $\mathrm{Nu}$ just below the crest on the pressure side of the flute, which becomes more dominant at the higher Prandtl number. In both cases there is a minimum in local heat-transfer coefficients towards the flute valley, although the position of this minimum is slightly further along the pressure side at the lower Prandtl number.

Table 1. - Mean Nusselt number values in smooth and fluted tubes.

\begin{tabular}{|l|c|c|}
\hline & $\operatorname{Pr}=0.71$ & $\operatorname{Pr}=5$ \\
\hline Smooth tube correlation & 66.1 & 144.3 \\
\hline Fluted tube & 70.5 & 213.0 \\
\hline Without area extension & 45.1 & 136.0 \\
\hline
\end{tabular}

The mean Nusselt numbers are shown in Table 1, together with values obtained from the Dittus-Boelter smooth-tube correlation $\mathrm{Nu}=0.22 \mathrm{Re}^{0.8} \mathrm{Pr}^{0.4}$. When the area extension $P /(2 \pi R)$ is included in the definition of $N u$, the computations show a small increase at $P r=0.71$, rising to an increase of almost $50 \%$ at $P r=5$. Without the area extension, however, the heat-transfer coefficients are much lower, being somewhat less than the smooth tube results. In contrast, YAMPOLSKY et al. [14] quote enhancements in heat transfer of the order of $60 \%$ (in water) even without including the area extension in the definition of $\mathrm{Nu}$.

\section{$\mathrm{V} \square$ CONCLUSIONS}

Detailed experiments have been reported of the velocity field arising in fully developed flow through spirally fluted tubing, including the near flute region. CFD studies of the same flow field have shown that 2 nd-moment closure is capable of predicting the dynamic field within the fluted 
tube with reasonable accuracy, including the non-linear variation of swirl velocity with radius. The variation of friction factor with Reynolds number (not shown) is also predicted accurately.

On the negative side the present predictions underestimate the enhancement of Nusselt number due to fluteinduced swirl. It is probable that the use of an eddy viscosity model within the low Reynolds number sublayer is the primary cause of this discrepancy and we shall shortly attempt to improve the predicted accuracy by replacing it with a second-moment closure. Another avenue for further work in trying to understand better the complex near-wall processes would be the inclusion of fluid property variations associated with the relatively steep gradients within the flute recesses.

\section{Acknowledgements}

The project has been funded by the SERC through Grants GR/G54740 and GR/F87711. Dr S C Cheah, Mr J Hosker, Dr D Cooper and Mr D C Jackson have all made important contributions to the success of the experimental programme. Authors names are sequenced alphabetically. A version of this paper has appeared in the proceedings of the 10th International Heat Transfer Conference, held in Brighton, UK, September, 1994.

\section{References}

[1] YAMPOLSKY J. - " Spirally fluted tubing for augmented heat transfer», General Atomic Company Report GAA15442, 1979.
[2] BABIKIAN D.S. and LARUE J.C. - « Measurements of turbulent flow in a spirally fluted tube ». Final Report Contract 787113 , University of California, Irvine.

[3] Barba A., Gosman A.D. and LAunder B.E. - "The prediction of heat-transfer performance in spirally fluted tubes: the turbulent regime $»$. Proc 1 st UK National Heat Transfer Conference, I Chem E Symp, 86, 695-706 (1984).

[4] HoskeR J. and JACKSON D.C. - * A Method of Fabricating Tubing of Complex Cross Section for Laboratory Flow Studies », UMIST Internal Report TFD/93/1, 1993.

[5] Cheah S.C., Cheng L., Cooper D. and Launder B.E. *On the Structure of Turbulent Flow in Spirally Fluted Tubes $»$, 5th IAHR Conference on Refined-Flow Modelling and Turbulence Measurement, Paris 7-10 September 1993.

[6] LIEN F.S. and LESCHZINER M.A. - « Second-moment modelling of recirculating flow with a non-orthogonal collocated finite-volume algorithm », Turbulent Shear Flows 8, pp. 205 222 (Ed F Durst et al.), Springer (1993).

[7] RHIE C.M. and CHOw W.L., AIAA J 211525 (1983).

[8] Patankar S.V. - *Numerical Heat Transfer and Fluid Flow », Mc-Graw-Hill, New York (1980).

[9] LeONARD B.P. - Comp Meth Appl Mech Engrg, 19. 59 (1979).

[10] VAN LeER B.J. - Comput Phys, 32, 101 (1979).

[11] LAUnder B.E. and Sharma B.1. - Lett Heat Mass Transfer, 1,131 (1974).

[12] Gibson M.M. and LAunder B.E. - J Fluid Mech, 86, 491 (1978).

[13] CRAFT T.J. and LAUNDER B.E. - AIAA J, 302970 (1992).

[14] Yampolsky J.S., LibBy P.A., Launder B.E. and Larue J.C. - " Fluid Mechanics and Heat Transfer Spiral Fluted Tubing ». Report GA-A17853 (1984). 